\title{
Analysis of the Inserting Way of National Culture in the New Media Advertising
}

\author{
Songshuang Duan
}

The School of Journalism and Communication, Guangxi University, Nanning, Guangxi, 530004, China

hunter2011@foxmail.com

Keywords: New Media, Advertisement, Natural Culture, Inserting

\begin{abstract}
The development of economic construction has brought civilization and creativity, but civilization and creativity also promote the progress of the society. Advertising media is a typical development of social civilization from the traditional paper media, radio station to the new media. Under the open style of the new media, advertising also has a more innovative ways of cultural transmission and more inclusive of external culture. In this paper, we will discuss the possibility, the relevant means and channels of communication to insert national culture into the new media advertising.
\end{abstract}

\section{Introduction}

The $21^{\text {st }}$ century is the era of new media art popular in the world. It not only brings a wide range spread of some school' s styles for human beings, but also a new idea for the production of social media. It emphasizes on the exploration of artistry, ideological level and conceptual, and also allows more cultural forms to be integrated in, to erect a bridge between human and art, and form a resonance.

\section{Analysis on the attribute of the national culture in the new media advertising}

National culture also has different inherent attributes in different development stages. It is different mainly based on the restrictions of polity, technology and region . Today is the time that new media communication is the first, so in this environment, that the national culture inserts into the new media advertising also reflects its own characteristics.

The inheritance of national culture.The essential core of cultural heritage is that culture has national character, so that the transmission of the national culture should be dynamic and lengthy process. After the new media and the main body of the national culture organic combined, cultural heritage, as a symbol, transfers the value recognition and cultural differences. New media advertising creates a continuous and complete mechanism for the national cultural heritage through the stability of its information technology, so in this process, the cultural heritage also builds a favorable internal and external development environment. It is in this logic that mankind can continue to obtain the power of life production, during the development of civilization, also inherit the national culture.

Regional nature of national culture. The ethnic culture that the new media advertising dissolved into in different regions is different, so for the whole country, national culture is spiritual bond to sustain the unity and common prosperity of the national spirit, in the outlook of Chinese cultural, Yin Guanghai summarized the connotation of national culture like this "It is the table level specific forms and deep-seated psychological values. ${ }^{[1] " ~ J u s t ~ a ~ s e n t e n c e ~ e x p r e s s e s ~ t h e ~ r e g i o n a l ~ c h a r a c t e r i s t i c s ~ t h e ~}$ national culture on media. Indeed, the national culture blend is also the integration of the two layers in this, and when the new media germination germinates in society, it is also the time that the national culture and regional culture are more extensive publicity.

The mass of national culture. With the rapid development of information technology in 21st Century, the national cultural exchange has become more popular, and the new media advertising is to create a communication platform, spread the history of all peoples, people's thinking and 
traditional culture to all people, and promote the harmonious situation of the national family, form a structure of Chinese cultural history, which is the most significant embodiment of the development of contemporary social structure and national civilization.

\section{Analysis of the performance of the national culture in the new media advertising}

New media is an open system with continuity development attributes. Digital technology, multimedia technology and other means of science and technology created a new form of the creation of new media, a mixture of business communication and the art aesthetic of new media advertising is such a new form of typical representative. And national culture in the new media advertising is fully utilized, forming a new media in the dissemination of important elements. It can be said that the new media advertising to the traditional national culture to be born again, carry forward and pass. This is the value of new media communication in social civilization development, but also the new media advertising with the help of the national culture elements in a better way of commercial communication and promote the continuous development of economy. Therefore, the national culture in the new media advertising embodied in the image is not only a diversity of image characteristics, but also a number of special symbolic elements, how to use them creatively, and will be perfectly implanted into the new media advertising is to focus on this article.

The way that the new media advertising inserts the image of the national culture. Wang Guowei once said, "everything is the language of the scene". This sentence profoundly expresses the importance of the elements of the image elements to the expression of emotion. That inserting the image features of national culture into the new media advertising in a variety of ways, can not only stimulate the audience's senses, but also convey the connotation of national culture implication to the audience. So the later mainly annotates the way and method application of new media advertising implanting national culture from color and characters the two elements of the national cultural image characteristics.

The implantation of the color element of the national culture

The performance of color in the new media is more brilliant, which directly stimulates the senses and emotions of the audience, and is an important symbol of the national culture in the new media advertising. From the national culture of the color, the new media in China is not closed and rational, but more open and emotional display of all kinds of art language of freedom and equality. Chinese people love on behalf of the festive Chinese red, for example, in the new media advertising will use interactive design program through red to represent the sound waves of people cheerful. Make the whole picture are full of festive red background. And in contrast, blue is reflected in the advertisement in the scene of melancholy sigh, reflecting the different colors of different national culture, quite appropriate.

In addition, the color expression in the new media advertising can describe some abstract symbolic meaning, and it can also create a real performance to express certain emotional feelings. For example, in the expression of the traditional architecture will be used to the simple brown, and in the expression of wealth and the palace will be a certain choice of gold. With the continuous evolution of the simulation and interactive technology, national culture color has been given more expressive force and meaning, they are no longer a one-way expression, but can connect with the audience through the information, so that the audience is not only the recipient of information, but also can manufacture information for the new media platform.

The implantation of the role elements of the national culture

There are many familiar and popular role in each national culture. These roles become no longer isolated after the birth of new media platform, but was given a more sense of the times and better expectations of the people for the world. Inserting the national culture into the new media advertising, the role elements is essential, because the role can have the hypothesis, but it is essential to reveal the nature of the national identity, for the audience to show the expression of cultural authenticity in advertising. For example, in the United States, the electronic game "radiation" used soft drinks in a space suit to attract the attention of the audience. In Figure 1, the more ancient 50's in the United States, and the women in modern space suits, although the whole screen with $2 \mathrm{D}$ rendering, but it 
reflects the fantasy romantic content of the United States in 50s that the game "radiation" want to explain, and the product the advertising want to express also represents the game's nuclear coke". The entire advertising integrates into a large number of the American traditional culture style, and the boundless fantasy Americans for the future world, and let the people who are familiar with the game know that it is the world view of style that "radiation" want to convey when they saw the ads, and it is the all-American cultural expression.

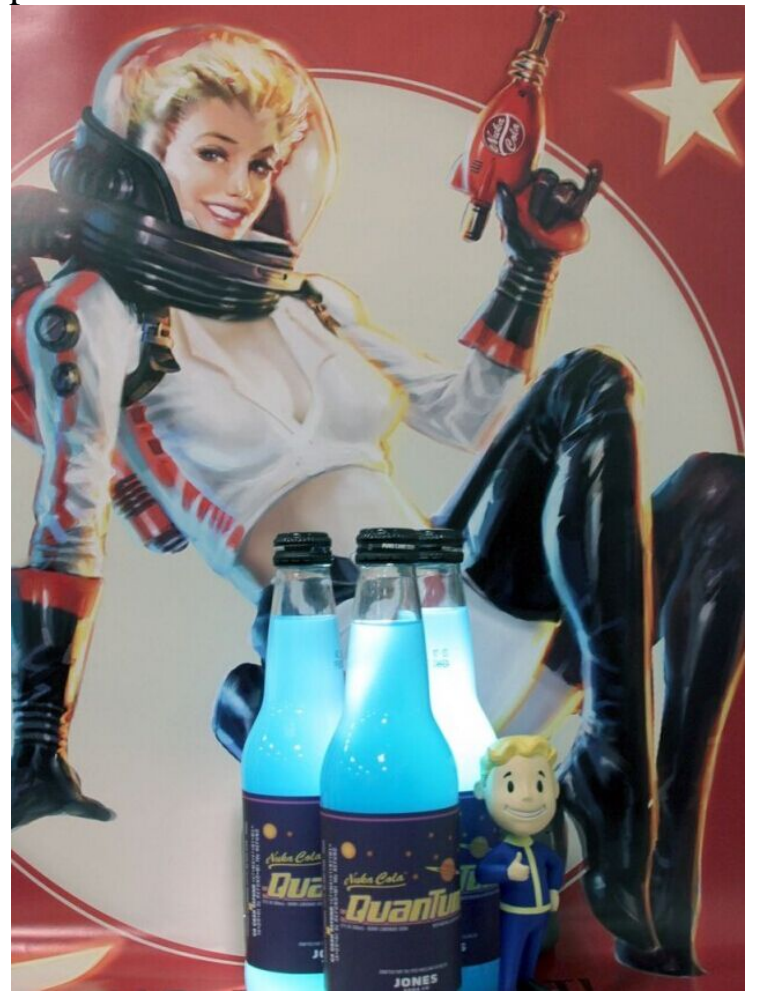

Fig. 1. Propaganda poster for nuclear coke ads of computer game Radiation

And in the support of new media technology, the transmission of the role is far more than that. For example, under the assist of the network technology HTML, ASP, PHP, and multi language, but also for the video site in the network advertising role elements, combined with the game engine and interactive technology, so that the role can interact with the audience, the greatest degree of weakening the audience for advertising. So, the new media advertising in the role of the national culture has been gradually moving towards the development of entertainment, integration and technology, it allows the audience to find a new focus in advertising.

The way that the new media ads implants the national culture symbol. The national culture of human beings can be expressed by means of symbols, which in a sense reflects the uniqueness of national culture, and it is a kind of personality which is opposite to the cultural differences. The new media advertising is implanted in the national culture symbol in order to reflect the balance of the advertisement in the dynamic, also through the national culture difference for people to bring greater impact force, in order to achieve the elimination of the effect of cultural understanding barrier.

The implantation of the ethnic customs of the national culture

Ethnic customs is an important performance point of national culture, which is a convention of the national cognition embodied in the relationship between man and man, to promote that the national culture is universally recognized and become a legitimate reason of natural common sense. The cultural differences between different nations, if you want to properly implanted in the new media advertising national customs and habits, we must stimulate the audience's national sentiment, causing the audience's resonance, to have the opportunity to achieve the advertising and marketing purposes. Based on this concept, the national customs and habits elements in the implantation of new media advertising is not only a monotonous emergence of an element, it needs to be integrated through a variety of cultural concepts and techniques to express, in order to maximize the value of the role of. 
For example, China Unicom will use its own CDMAIX network technology for remote information monitoring, some of the national culture of the custom symbols into the mobile media advertising, such as with the Chinese wind of the national personalized on-demand service, according to the audience's preferences, the location of the region customs and other related music and content, etc.. In the process of advertising communication, China Unicom has grasped the close nature of the national culture and the people's daily life. With the new media platform, the new media platform has achieved the effect of spreading its own brand at any time.

The implantation of the cultural symbol of the national culture

In many online games, the cultural symbol with Chinese characteristic is very common, such as the Chinese dragon. Dragon as a symbol of culture, represents the supreme authority of the symbol in Chinese traditional culture, this symbol in contemporary society communication, there are a variety of applications. In network game advertising, the dragon can not only create beauty effect communication realm for the national culture, may also give the unique cultural property to the role through new media technology into a role of clothing, moves names. This cultural closeness to the game between the advertising and the distance between the players, to stimulate interest in the effect of players. Modern new media network technology such as VC, 3D, HTML5 and others games to prepare the engine, are able to create such a creative way of a Chinese national culture totem image, for new media advertising to enhance the effectiveness and appeal ${ }^{[2]}$.

\section{Channel analysis of new media advertising implanted in national culture}

The national culture is implanted into the new media advertising to carry out propaganda, its purpose is clear to maintain and pass forward the national culture, so that it can have a more long-term future. Today, the use of the platform of the school's multimedia education culture, can play a role for the development and the extending of the national culture. Although the school is not any media, but in the new education reform system of education platform has been gradually moving towards the development of digital and multimedia, and students represent the future of the country, so with this new media platform to promote national culture and then appropriate. The education experts in our country call this kind of national culture propaganda way is called "based on the spread of education of new media into daily life" ${ }^{[3]}$. In our country, the use of traditional national culture festival in combination with education new media platform to launch advertising, the popularization of national holiday culture knowledge is the more commonly used in many areas of education, which promotes the youth generation of the national culture of mutual exchange, and through the new media to build the opportunity. It is this kind of national future talent exchange that gives a new meaning of new media advertising propaganda in the campus.

As for the international output of our national cultural, new media advertising is also popular. For example, in North America, the new media advertising of Chinese classics and Confucius institute have a very important meaning in local. Chinese-American popularizes Chinese traditional culture to the United States and the world in the way of the spread of the popular culture and new media dissemination, to design the advertising with Chinese characteristics through the network and AE technology, and spread in the community, schools and other public places. And about that the Chinese culture and Chinese teaching has also set up a digital network platform, the advertising design is quite the United States, also makes more Americans interested and willing to take the initiative to contact the Chinese national culture, to achieve a non commercial cultural exchanges between the two countries. Although this international new media advertising culture is not a national culture of implantation, but it has created a more valuable thing, that is, the Chinese and American cultural friendship between the two peoples, so that Chinese culture can flourish overseas.

\section{Summary}

The new media advertising is the product of human science and technology with the modern social consciousness, and it is a wonderful chemical reaction with the product of human history and civilization, which makes the national society gradually shifted from economic to cultural economy, 
and makes the modern society more civilized and more emotional. Therefore, in the new media platform for the implantation of national culture is able to meet the needs of contemporary people's emotional needs and promote the national interests of the connotation of performance means, but also to the traditional and contemporary culture, which is a harmonious melting of contradictions, with a landmark.

\section{Acknowledgments}

The Project Sponsored by Scientific Research Foundation of Guangxi Zhuang Autonomous Region for colleges and universities "Research on the Implantation and communication of Ethnic Culture in new media advertising", Grant No.200103YB011;The Project Sponsored by the Scientific Research Foundation of GuangXi University, Grant No.XGS110007.

\section{References}

[1] Zhang Ting,Chu Zi'an. Research on the problem of national culture in the new media advertising. Hundred Schools in Arts,2013,(z1): 180-182.

[2] Wang Kaiqing,Wang Jinxiu. The deep structure and properties of national culture in new media advertising. Social Scientist,2013,(2): 148-150.

[3] Chu Zi'an. Research on the national culture in the new media advertising. Guangxi Normal University, 2012,23-32.

[4] Shu Yongping. New media advertising communication. Shanghai: Publishing House of Shanghai Jiao Tong University,2015.

[5]Dick wrote,Cai Jing translated. Network Society--the social aspects of new media. Beijing: Publishing House of Tsinghua University,2014. 